TURIZAM

Volume 22, Issue 2

71-83 (2018)

ORIGINAL

SCIENTIFIC PAPER

\title{
Perception of Inbound Backpackers towards Urban Superstructure: A Case in Jakarta (Indonesia)
}

\author{
Roozbeh Babolian Hendijani ${ }^{\mathrm{A}}$ \\ Received: February 2018 | Accepted: May 2018 \\ DOI: $10.5937 / 22-17529$
}

\begin{abstract}
A tourist's experience is the factor that would determine the satisfaction of a trip and it is important for destinations to achieve success in the highly competitive tourism marketplace. Backpacking as one of the modes of travelling is getting attention among scholars. In Indonesia, the numbers of backpackers are increasing year by year; however there is still a lack of study about their satisfaction levels based on their backpacking experience, mainly due to the misconception that this segment of the market has low value. Therefore, the objectives of this research are to identify the most affecting experience of backpackers' satisfaction based on superstructure in Jakarta, and to know the effect of satisfaction on their decision to revisit. The target of this research is inbound backpackers from Jakarta, Indonesia. This research employs a quantitative method with the usage of self-administered questionnaires to gather the data from 160 backpackers in Jakarta's international airport and some tourist attractions around Jakarta. Different analyses such as exploratory factor analysis, multiple linear regression, and descriptive analysis were employed. The results of this study identified some factors which have a significant impact on satisfaction. It is proposed that for the sustainability of tourism development, future planning should consider the importance of backpackers as a considerable target market. The findings would be helpful to various stakeholders such as marketers and hospitality businesses in order to understand and improve tourists' visit experience in future.
\end{abstract}

Keywords: Backpackers, Superstructure, Satisfaction, Revisit Intention, Jakarta

\section{Introduction}

Tourism is a pleasurable activity pursued by modern consumers. It is basically an experiential sensation resulting in unique and pleasurable memories. Tourism could also help to represent a destination to different countries based on the nation's art, tradition, culture and its hospitality (Holloway et al., 2009; Weaver, Lawton, 2014). Tourism has become an important sector in many countries' economies because it generates revenue, job opportunities and creates the need for associated services such as infrastructure and superstructure which can be used

A Bina Nusantara University, Faculty of Economics \& Communication, Hotel Management Department, Jakarta, 11480, Indonesia H-3515 Miskolc, e-mail: rhendijani@binus.edu 
by both tourists and local residents. Tourism marketers and stakeholders are facing remarkable challenges in creating unique, pleasurable and memorable experiences for tourists during their visit. It is regarded as a highly personal and subjective experience which is co-created by tourists through interaction with the people, environment, objects and technologies (Bagdare, 2016). Understanding those interactions will help destinations to create proper strategies for effective management.

Understanding the behavior of tourists has been an important subject in tourism studies for decades (Cortez-Jimenez, 2008; Hendijani, Sulistyo, 2017; McIntosh, Thyne, 2005; Woo et al., 2015). Tourists generally make some form of evaluation about their visit experience. In order for tourists to return home with positive memorable experiences, the destination must ensure that they had a positive time during their visit. The study of tourism experience has become important because of the highly competitive marketplace for this growing industry (Kim, 2017; Kim, Ritchie, 2014). To attract tourists, it is important to spread information through positive word of mouth about tourist satisfaction relating to particular activities or experiences (Babolian Hendijani et al., 2013; Oppermann, 1997; Poria et al., 2009). Positive customer experiences result in good memories and satisfaction which will have a major effect on future behavior. The level of satisfaction derived from different activities has been found to have an impact on the intention to revisit a destination (Chen, Tsai, 2007), which could result in higher income generation for the destinations. Previous studies stated that positive and pleasurable experience of tourists are related with benefits to the tourists as well as to destination in terms of satisfaction (Alegre, Garau, 2010), loyalty (Yuksel, 2001), recommendation (Weaver, Lawton, 2014), profitability (Gretzel et al., 2000), and its destination image (Baloglu, Managaloglu, 2001; Gross, Brown, 2006).

Tourists who visit a destination are expected to participate in various activities and engage with numerous products and services during their holiday. During and after their visit, it is anticipated that they would evaluate their visit experiences based on their encounters with the destination's products and services. The performance of these products and services are important in determining the outcome of tourists' visit experience (Kim, 2017). Hence, a meaningful visit experience will depend on the capability of the destination to deliver acceptable provisions that can fulfil their needs and wants during the vacation.

It is discussed in tourism literature that tourists' experiences are the factors that would determine their satisfaction (Hendijani, 2015; Jaume, Joaquin, 2009) and satisfaction has been recognized as having a strong influence on revisit intention (Chen, Tsai, 2007; Kim, 2017; Shirazi, Som, 2010). It is obvious that information about the visitor's future behavior is very important for tourism product development. If the destination knows nothing about it, it will be hard to plan the best appropriate products and services for the destination, to attract more repeat tourists, and assure success. Many studies have been explored to find out a destination's performance by analyzing tourist satisfaction from different aspects. They would attempt to uncover the performance of the attribute destination and discover unexpressed tourists' impression (Jaume, Joaquin, 2009; Yoon, Uysal, 2005). Earlier studies suggest that memorable tourism experiences are determined by a wide range of factors such as attractions, accessibility, activities, environment management, infrastructure and superstructure (Buhalis, 2000; Kim, 2014; Mossberg, 2007).

One of the vital features which affect the experience of tourists is the superstructure of the destination. Destination superstructure includes those facilities that have been developed especially to respond to the demands of tourists (Goeldner, Ritchie, 2012). The most obvious examples include accommodation, restaurants, transportation and major attractions. Previous 
studies (Carlsen, 1999; Gunn, 1997; Mill, Morrison, 2002; Loker-Murphy, Pearce, 1995; Weaver, Lawton, 2014) identified three main pieces of evidence regarding superstructure (accommodation, transportation and restaurants) for the proliferation of backpackers all over the world. Since these factors directly or indirectly can affect tourist experiences, it is worth knowing about their effect on destinations which are growing in the tourism industry.

As this research is more focused on the experience findings, backpackers who were concerned about an 'authentic experience' were chosen as the target for the research. This segment of travelers are more independent and willing to encounter different activities and mingle with local residents and experience the way they live their routine life. In 2012, \$217 billion of the \$1, o88 trillion tourism 'spend' worldwide came from young backpackers, which means they now represent $20 \%$ of international tourism (Mohn, 2013). Other characteristics of backpackers are an emphasis on meeting locals and other travelers where word-of-mouth marketing would be influential (Pearce, 2005). Therefore backpackers' experience has a very significant effect on a country's tourism promotion, especially in destinations which are experiencing the growth of this industry such as Indonesia.

The number of backpackers in Indonesia has steadily grown in the last few years because of the enormous amount of adventurous attractions (Euromonitor International, 2012; Wonderful Indonesia, 2017). Although the number of backpackers in Indonesia keeps increasing, there is still a lack of study about the satisfaction levels of their backpacking experience while in Indonesia and specifically in Jakarta as the capital city. Since Jakarta is famous as an industrial city and economic hub of the country, the government decided to change the image of this city to a destination which offers a variety of leisure and cultural activities and attractions (Wonderful Indonesia, 2017). Nowadays, Jakarta is not only known for its historical sites, but it is also well-known as a modern city with skyscrapers and shopping centers, and thus it has become a vacation destination for international tourists. The increasing popularity of Jakarta for tourists provides an opportunity for the government and society to prepare the attributes that are able to increase tourists' satisfaction. Examining how Jakarta as a tourism destination is perceived by tourists is particularly important; an understanding of not only the appropriateness of existing destination marketing and promotional strategies, but also tourists' satisfaction and post-trip behavior is required.

Research into backpacking has significantly lagged behind general tourism studies, mainly due to the misconception that this sub-market has low value (Cohen, 2003; Richards, Wilson, 2004). This has resulted in an information gap for understanding backpackers' experience, specifically in Jakarta which attempts to attract more of this segment of the tourism market. Therefore, the main objectives of this research are to identify satisfaction levels based on backpackers' experiences towards superstructure and to know if this satisfaction will result in an intention to revisit Jakarta.

By understanding backpackers' experience, it would attempt to uncover the performance of the attribute destination and find out unexpressed backpackers' impressions. Since previous studies about backpackers (Loker-Murphy, Pearce, 1995; Markward, 2008; Toxward, 1999) are mostly focused on examining descriptive characteristics and behavior, this study focuses more on identifying international backpackers' experience during their stay in Jakarta. 


\section{Methodology}

To measure the level of satisfaction of backpackers based on their experience with superstructure and their intention to revisit Jakarta, self-administered questionnaires consisting of four segments (experience, satisfaction, intention to revisit, and socio-demographic items) were distributed randomly to tourists waiting for departure in Soekarno-Hatta International Airport and some popular tourist areas around Jakarta. Most of the respondents were selected in the airport departure area because they already had experience during their holiday in Jakarta before returning to their home countries. A convenience sampling method was applied for this research. The questionnaire was developed based on a review of previous literature and was modified by the researcher using a literature review and adjusted for content validity. The first part of the questionnaire consisted of thirty questions and measured various aspects of superstructure experiences (transportation, accommodation, and food \& beverages) using a fivepoint Likert scale ( $1=$ strongly disagree to $5=$ strongly agree). Questions in this segment were based on previous research (Babolian Hendijani et al., 2013; Jalis et al., 2009; Kivela, Crotts, 2009; Morachat, 2003). The second and third segments consisted of six questions that measured the overall satisfaction and intention to revisit of backpackers (Babolian Hendijani, 2016; Jalis et al., 2009). The last part of the survey consisted of questions related to the socio-demographic characteristics of the participants (age, gender, country of origin, marital status, occupation, and length of stay). Since the respondents of this study were international backpackers to Indonesia, the survey questionnaire was prepared in the English language.

To ensure the reliability and validity of the questionnaire, a pilot test was conducted using 20 randomly selected tourists from a few popular shopping malls around Jakarta. After running a statistical reliability test of Cronbach's alpha (experiences $=.734$, satisfaction $=.812$, intention to revisit=.730), it was found that the instrument had an acceptable reliability factor for conducting research. Data was collected between May and July 2016. Out of 160 collected questionnaires and after removing incomplete sets of questionnaires, 150 (88.24\%) valid questionnaires were used for subsequent analysis. In addition to the usual descriptive analysis of means, standard deviations, and frequencies, an exploratory factor analysis (EFA) was performed to determine underlying factors. The factor scores derived from the EFA were used in the subsequent multiple linear regression analysis.

\section{Results and Discussion}

The profiles of the respondents indicated that the number of male backpackers (58.7\%) was slightly higher than females. The ages of respondents ranged between 18 and 32 years old (mean $=25$ ) and in terms of marital status, the majority of them were single (86.7\%). This finding is supported by a previous study (Paris, Teye, 2010) which mentioned most of the respondents (88.8\%) of backpacker respondents were single). Most of the respondents were from Europe (43.3\%), and the majority of backpackers were first time visitors to Jakarta (71.3\%). Table 1 presents the profile of respondents. 
Table 1. Profile of Respondents

\begin{tabular}{|l|l|c|}
\hline Categ & Frequency & (\%) \\
\hline \multirow{3}{*}{ Gender } & Male: 88 & 58.7 \\
& Female: 62 & 41.3 \\
\hline \multirow{5}{*}{ Continent } & Minimum: 18 & \\
& Maximum: 32 & \\
& Mean: 25.4 & 26.0 \\
& Asia: 39 & 43.3 \\
& Europe: 65 & 26.0 \\
\hline \multirow{2}{*}{ Marital Statues } & Oceania: 39 & 16.7 \\
& America: 25 & 2.7 \\
\hline \multirow{5}{*}{ Job } & Africa: 4 & 86.7 \\
& Single: 130 & 13.3 \\
\hline Married: 20 & 41.3 \\
\hline \multirow{3}{*}{ Length of Stay (Days) } & Student: 62 & 34.0 \\
& Self-employed: 51 & 21.3 \\
& Government Job: 32 & 3.3 \\
\hline \multirow{2}{*}{ Frequency of Visits } & Unemployed: 5 & \\
& Minimum: 2 days & \\
\hline & Mean: 20.6 Days & 71.3 \\
& First Time: 107 & 28.7 \\
\hline
\end{tabular}

Exploratory factor analysis was performed on different superstructure attributes to determine the underlying factors. The first analysis was conducted on nine accommodation experience attributes. The results are presented in Table 2 . Barlett's test of sphericity was used to ensure that the variable factors were uncorrelated. The value of the test was $594.932(\rho=.000)$, suggesting that it was appropriate to conduct factor analysis. The Kaiser-Meyer-Olkin measure of sampling adequacy was .810 , which indicated that the factor model was acceptable. Kaiser's varimax rotation revealed 2 factors (variance explained $=61.1 \%$ ) which were extracted from the original 9 variables (loading the variables was at least 0.5 ).

The first factor was labeled 'accommodation social environment' and demonstrated the most variance $(45.6 \%)$ and had a reliability coefficient of .877 . This factor included seven items (friendliness, helpfulness, communication, value, facilities, cleanliness, and safety). The backpackers indicated that the environment of accommodation contributed to overall satisfaction. Factor 2 was 'accommodation accesses. This factor accounted for approximately $15.5 \%$ of the variance in the data with two variables (culture and accessibility). However, because of the low reliability coefficient of the two variables (.553), these components were separated for the next analysis. In subsequent analysis these items were labeled as 'accommodation culture' and 'accommodation location'. 
Table 2. Factor Loading and Reliability of Accommodation Attributes

\begin{tabular}{|l|c|c|}
\hline Items & Factor 1 & Factor 2 \\
\hline Friendliness & .776 & \\
\hline Helpfulness & .804 & \\
\hline Communication & .702 & \\
\hline Value for money & .744 & \\
\hline Facilities acceptable & .823 & \\
\hline Cleanliness & .729 & \\
\hline Safety & .740 & .839 \\
\hline Representing culture & & .806 \\
\hline Accessibility & & .553 \\
\hline Reliability coefficient & .877 & \\
\hline
\end{tabular}

The second analyzed superstructure item was the transportation experience in Jakarta. The results are depicted in Table 3. The results revealed the value of Bartlett's sphericity is 355.873 $(\rho=.000)$, which indicates that the distribution of values in the initial measure of transportation experience was acceptable for conducting factor analysis. The value of Kaiser-Meyer-Olkin was .737, which indicated that the factor model was acceptable. Kaiser's varimax rotation revealed two factors (variance explained $=46.2 \%$ ) and were extracted from the original 10 variables. The first factor was labeled 'transportation surroundings' and demonstrated the most variance $(32.9 \%)$ and had a reliability coefficient of .713. This factor included five items (friendliness, helpfulness, communication, cleanliness, and time). Factor 2 was 'transport access' and accounted for approximately $13.3 \%$ of the variance in the data with three variables (values, facilities, and accessibility) and a reliability coefficient of .700. The important role of accessibility of transport and transport fees was stated in previous studies (Della Corte, 2013; Wan, Chan, 2013). The two items of 'safety' and 'different system' were used separately in subsequent analyses since they were not included in the factor loading.

Table 3. Factor Loading and Reliability of Transportation Attributes

\begin{tabular}{|l|c|c|c|}
\hline Items & Factor 1 & Factor 2 & Factor 3 \\
\hline Friendliness & .818 & & \\
\hline Helpfulness & .817 & & \\
\hline Communication & .600 & & \\
\hline Cleanliness & .589 & & \\
\hline Time & .500 & .706 & \\
\hline Value for money & & .772 & \\
\hline Facilities acceptable & & .641 & \\
\hline Accessibility & & .464 & \\
\hline Safety & & & \\
\hline Different system & .713 & .700 & \\
\hline Reliability coefficient & & & \\
\hline
\end{tabular}

The third analyzed superstructure item was food and beverage experience in Jakarta. The results are depicted in Table 4. Results revealed the value of Bartlett sphericity was 426.179 $(\rho=.000)$, which indicated that distribution of values in the initial measure of food and bever- 
age experiences was acceptable for conducting factor analysis. The value of Kaiser-Meyer-Olkin was .749, which indicated that the factor model was acceptable. Kaiser's varimax rotation revealed one factor (variance explained $=39.32 \%$ ) and three separated items were extracted from the original 9 variables. The first factor was labeled 'F\&B atmosphere' and had a reliability coefficient of .814. This factor included six items (friendliness, helpfulness, facilities, fresh ingredients, cleanliness, and communication). Friendliness of restaurant staff and their good communication with visitors were found to be an important aspect for tourists when dining out at destination (Kotler et al., 2014). Factor 2 consisted of two items in which one of them had factor loading of less than .05 ('value for money') and factor 3 consist of only one item. Therefore, the three items in factor 2 and factor 3 which were not included in the factor loadings were culture, value for money, and accessibility and they were analyzed in subsequent multiple linear regression as independent items.

Table 4. Factor Loading and Reliability of Food and Beverage Attributes

\begin{tabular}{|l|c|c|c|}
\hline Items & Factor 1 & Factor 2 & Factor 3 \\
\hline Friendliness & .796 & & \\
\hline Helpfulness & .784 & & \\
\hline Facilities acceptable & .750 & & \\
\hline Fresh ingredients & .689 & & \\
\hline Cleanliness & .684 & & \\
\hline Communication & .517 & .769 & \\
\hline Culture & & .433 & \\
\hline Value for money & & & \\
\hline Accessibility & .814 & & \\
\hline Reliability coefficient & & & \\
\hline
\end{tabular}

To assess the influence of superstructure experiences on the overall satisfaction of backpackers, multiple linear regression analyses was performed to estimate the coefficients of the linear equation that best predict overall satisfaction. The regression model was significant $(\mathrm{F}=$ 12.124, $\rho=.000$ ). The regression results are depicted in Table 5 .

Table 5. Regression for Overall Satisfaction

\begin{tabular}{|c|c|c|c|c|c|c|}
\hline $\begin{array}{l}\text { Dependent } \\
\text { variable }\end{array}$ & Independent Variables & $R\left(R^{2}\right)$ & Unstandardized & Standardized & Sig. & $\mathrm{t}$ value \\
\hline \multirow{11}{*}{ 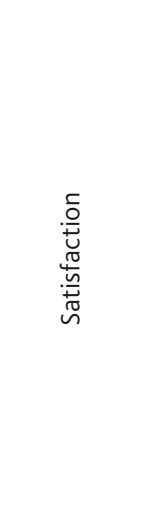 } & Accommodation social environment & $70.1(49.1)$ & .191 & .159 & .040 & 2.077 \\
\hline & Accommodation culture & & .003 & .003 & .963 & .047 \\
\hline & Transport access & & -.147 & -.117 & .149 & -1.451 \\
\hline & F\&B accessibility & & .215 & .219 & .004 & 2.906 \\
\hline & F\&B culture & & .092 & .097 & .157 & 1.423 \\
\hline & F\&B value for money & & -.121 & -.112 & .142 & -1.477 \\
\hline & F\&B atmosphere & & .380 & .293 & .000 & 3.638 \\
\hline & Transportation system & & -.070 & -.085 & .195 & -1.303 \\
\hline & Transport safety & & .090 & .088 & .207 & 1.269 \\
\hline & Transportation surrounding & & .266 & .219 & .004 & 2.918 \\
\hline & Accommodation location & & .217 & .236 & .001 & 3.396 \\
\hline
\end{tabular}


Based on results, superstructures attributes contributed $49.1 \%$ of backpackers' overall satisfaction. The results indicated ' $F \& B$ atmosphere' had the highest effect $(\beta=.293, \rho=.000)$ on overall satisfaction of backpackers, followed by 'accommodation location' ( $\beta=.236, \rho=.001)$, 'location of F\&B' and 'transportation surroundings' $(\beta=.219, \rho=.004)$, and 'accommodation social environment' $(\beta=.159, \rho=.040)$. The findings were supported by a previous study about the importance of food ingredients and cleanliness of restaurants on overall satisfaction of tourists (Babolian Hendijani, 2016). Another aspect of restaurants which affected the satisfaction of tourists was its accessibility. Due to the large number of restaurants in Jakarta, it is easy for tourists to find restaurants nearby. It was also mentioned in a previous study by Babolian Hendijani (2016) that easy accessibility to restaurants has an effect on the satisfaction of tourists. In terms of the environment, most backpackers may be surprised to learn of the variety of street food. O'Reilley (2006) stated that backpackers are new-experience seekers. Therefore the people or staff and the environment of food and beverages would affect their satisfaction.

The findings of this study are consistent with recent studies which mentioned the importance of staff friendliness, cleanliness of the place, and safety of accommodation (Bodet et al., 2017; Buonincontri et al., 2017; Ren et al., 2016). Since the number of tourists to Jakarta are increasing, the government has invested in building accommodation. It was also found that the location of accommodation and its distance to tourist attractions has an effect on the satisfaction of travelers (Martin et al., 2016). In terms of transportation, the findings of this study were supported by previous research (Martin et al., 2016) which indicated the friendliness and helpfulness of drivers will positively affect the quality of the experience. Previous research by Page and Lumsdon (2004) agreed that transport in a tourist destination has a big impact on the tourism experience.

In order to answer the last objective of this research, next regression analysis was conducted to know the effect of satisfaction on the intention to revisit the Jakarta. From the results depicted in Table 6, backpackers were highly satisfied with the superstructure experiences and would revisit Jakarta.

Table 6. Regression for Intention to Revisit

\begin{tabular}{|c|c|c|c|c|c|c|}
\hline Independent & Dependent variable & $\mathbf{R}\left(\mathbf{R}^{2}\right)$ & Unstandardized & Standardized & Sig. & $\mathbf{t}$ value \\
\hline Satisfaction & Intention to revisit & $70.2(49.2)$ & .694 & .702 & .000 & 11.981 \\
\hline
\end{tabular}

Based on the results, satisfaction contributed $49.2 \%$ of backpackers' intention to revisit Jakarta. Satisfaction was significantly related to revisit intention $(\beta=.702, \mathrm{p}=.000)$. This finding was supported by previous studies (Hui, Ho, 2007; Kozak, Rimmington, 200o; Yoon, Uysal, 2005), which if there is a positive experience and reviews accumulated in a destination, the higher chance the revisit intention is going to be.

\section{Conclusion}

Tourism experience is a pleasurable and measurable phenomenon and it is gaining wider importance in the era of the 'experience economy'. The main aim of investigating factors affecting backpackers' satisfaction and intention to revisit with superstructure experience was to understand the effect on overall tourism experiences. Although tourism research acknowledges the importance of knowing different aspects of experiences (Weaver, Lawton, 2014), the existing literature is limited to investigating the importance of superstructure experiences by tour- 
ists in Jakarta as a fast-growing destination for tourism. This study has made several important contributions to existing knowledge on this topic. First, it reveals different attributes of superstructure that influence backpackers' satisfaction and some other attributes which need to be maintained in future. Tourism destinations are experiencing a challenge to compete with each other in order to attract tourists (Chi, Qu, 2008; Kim, 2017). Therefore, to know what factors affect the satisfaction of tourists are important. Researchers have reported that customer satisfaction is an important factor for the success of a destination (Barnes et al., 2016; Kim, Ritchie, 2014; Weaver, Lawton, 2014). Therefore, it is important to know which dimensions of superstructure experience impact the views of backpackers and make their trip more satisfying. Yoon and Uysal (2005) pointed out that tourist satisfaction must be a basic parameter used to evaluate the performance of a tourism destination. If tourism marketers and stakeholders are able to identify how components of a product or service affect backpacker satisfaction, they may be able to change the tourist experience by developing appropriate marketing strategies to maximize their satisfaction, and motivate them to revisit the same destination. Understanding tourist experiences can help destination marketers to evaluate their ability to deliver better experiences for tourists, and encourage managerial actions that aim to secure the loyalty and revisit intention of tourists. Hsu (2003) found that overall satisfaction and intention to recommend and revisit a destination are largely a function of the types of benefits tourists experience during their visit. Therefore, tourism destinations need to promote these benefits to both current and potential tourists. Destination marketers should use their knowledge of determinants that affect outcome variables to develop products and services which satisfy tourists' desires.

The superstructure of a destination is an essential tourism product which directly or indirectly can affect the tourism experience but studies on its influence are limited. Therefore, this study was undertaken to bridge the knowledge gap in this phenomenon. This study identified the attributes of superstructures that make the travel experience a pleasant one for backpackers. The findings of this study confirmed that superstructure experiences affect overall tourist satisfaction and also the factors which need to be improved in order to maximize the tourist experience. The results suggested that several variables (i.e. F\&B atmosphere, F\&B location, transportation surroundings, accommodation location, and accommodation social environment) are important destination superstructure attributes that likely affect the satisfaction of tourists. There are also some variables which did not affect backpackers' satisfaction (i.e., accommodation culture, F\&B culture, F\&B value for money, transport access, transport system, and transport safety) which challenge practitioners and researchers in destination management. In terms of satisfaction that was associated with backpackers' behavioral intention to revisit, a significant and positive relationship was found which is consistent with the result of previous research on tourists' behavior (Kim et al., 2010).

Even though previous studies identified the importance of visual culture in designing the accommodation for pleasing the tourists, the findings of this study identified the decoration of accommodations as not appealing for tourists. The findings also indicated the backpackers have not had a positive experience with the transport system in Jakarta especially in terms of its safety and therefore, considerable efforts should be made to improve the current situation. For example tourism marketers and stakeholders should adopt traditional methods such as employee training to enhance the standard of services. Moreover, policy makers and government agencies need to invest in education of both local residents and tourists in order to improve aspects of safety, hygiene, and traffic. Another aspect which negatively affects the experience of tourists were food serving and price of food. Cohen and Avieli (2004) suggested that the mode of preparation and serving may sometimes be a recent invention intended to 
impress or attract the tourists. Thus, restaurant operators may exhibit different food preparation and serving processes, resulting in different and unique experience for tourists. The findings of this study present important implications for the marketers for designing strategies and benefitting from positive experiences. Suitable elements can be incorporated for better interactivity with tourists to create a unique, pleasurable and memorable tourism experience.

Second, in terms of theoretical implications, this study added to the body of literature in backpacker's satisfaction and revisit intention based on the experience of superstructure in Jakarta. One significant theoretical contribution of this study is that the findings add to a growing body of literature on the superstructure attributes of destinations that affect the satisfaction of visitors. The findings of this study could be used as a foundation for future research on a similar topic and should provide scholars with new insights into the role of the superstructure attributes of destination associated with memorable experiences.

While doing this research, some limitations were encountered. First of all, backpackers were surveyed in Jakarta's international airport and some tourism areas around Jakarta. Future studies may consider carrying out surveys at other tourist destinations such as Bali or Lombok to enhance the findings of this research. Second, this study was based on a quantitative approach. It is suggested future studies apply a qualitative approach to get more insights regarding backpackers' experiences during their visit. The last limitation was the analyzed variables. This research only focused on superstructure experiences. It is suggested that future studies examine other factors such as participated activities and motivation of backpackers to choose Indonesia as their backpacking destination.

\section{References}

Alegre, J., Garau, J. 2010. Tourist satisfaction and dissatisfaction. Annals of Tourism Research 37(1), 52-73.

Babolian Hendijani, R. 2016. Effect of Food Experience on Tourist Satisfaction: The case of Indonesia. International Journal of Culture, Tourism and Hospitality Research 10(3), 272282.

Babolian Hendijani, R., Sambasivan, M., Ng, S. I., Boo, H. C. 2013. Effect of gastronomy experience on overall satisfaction: differences between backpackers and mass tourists in Malaysia. In: Imm, N. S., Hassan, H., and Yiing, L. S. (Eds.) Reading on Hospitality and Tourism Issues. McGraw Hill, Malaysia, 107-123.

Bagdare, S. 2016. A conceptual framework for management of tourism experience. Imperial Journal of Interdisciplinary Research 2(6), 718-722.

Baloglu, S., Mangaloglu, M. 2001. Tourism destination images of Turkey, Egypt, Greece, and Italy as perceived by US-based tour operators and travel agents. Tourism Management 22(1), 1-9.

Barnes, S. J., Mattsson, J., Sorensen, F. 2016. Remembered experiences and revisit intentions: A longitudinal study of safari park visitors. Tourism Management 57, 286-294.

Bodet, G., Anaba, V., Bouchet, P. 2017. Hotel Attributes and Consumer Satisfaction: A Cross-Country and Cross-Hotel Study. Journal of Travel \& Tourism Marketing 34(1), 52-69.

Buhalis, D. 200o. Marketing the competitive destination of the future. Tourism Management 21(1), 97-116. 
Buonincontri, P., Morvillo, A., Okumus, F., Van Niekerk, M. 2017. Managing the experience co-creation process in tourism destinations: Empirical findings from Naples. Tourism Management 62, 264-277.

Carlsen, J. 1999. A system approach to island tourism destination management. Systems Research and Behavioral Science 16(4), 321-327.

Chen, C., Tsai, D. 2007. How destination image and evaluative factors affect behavioral intentions? Tourism Management 26(1), 45-56.

Chi, C. G. Q, Qu, H. 20o8. Examining the structural relationships of destination image, tourist satisfaction and destination loyalty: An integrated approach. Tourism Management 29(4), 624-636.

Cohen, E. 2003. Backpacking: Diversity and change. Journal of Tourism \& Cultural Change 1(2), 95-110.

Cohen, E. 1979. A phenomenology of tourist experiences. Sociology 13(2), 179-201.

Cohen, E., Avieli, N. (2004). Food in tourism: Attraction and impediment. Annals of Tourism Research 31(4), 755-778.

Cortez-Jimenez, I. 2008. Which type of tourism matters to the regional economic growth? The cases of Spain and Italy. International Journal of Tourism Research 10(2), 127-139.

Della Corte, V. 2013, Imprese e sistemi turistici: il management, II Edizione, Egea, Milano.

Euromonitor International. 2012. Passport. Tourism Flows Inbound in Indonesia, 5.

Goeldner, R., Ritchie, B. 2012. Tourism: Principles, Practices, Philosophies. Wiley, United States.

Gretzel, U., Yuan, Y. L., Fesenmaier, D. R. 200o. Preparing for the new economy: advertising strategies and change in destination marketing organizations. Journal of Travel Research 39(2), 146-156.

Gross, M. J., Brown, G. 2006. Tourism experiences in a lifestyle destination setting: the roles of involvement and place attachment. Journal of Business Research 59(6), 696-700.

Gunn, C. (3rd Eds.) 1997. Vacationscape: Developing tourist Areas. Washington D.C: Taylors \& Francis.

Hannam, K., Ateljevic, I. 2008. Backpacker Tourism - Concepts and Profiles. Channel View Publications, United Kingdom.

Hendijani, R. B. 2015. Push and pull factors of inbound tourists to Indonesia. Journal of Environmental Management \& Tourism 6(2), 157-163.

Hendijani, R. B., Sulistyo, L. I. H. 2017. Tourists' Expectation and Perception Regarding Holiday in Jakarta, Indonesia. Journal of Environmental Management and Tourism 8(4), 919-926.

Holloway, J. C., Humphreys, C., Davidson, R. 2009. The Business of Tourism. Prentice Hall, England.

Hsu, C. H. 2003. Mature motorcoach travelers' satisfaction: a preliminary step toward measurement development. Journal of Hospitality \& Tourism Research 27(3), 291-309.

Hui, T. K., Ho, A. 2007. Tourists' satisfaction, recommendation and revisiting Singapore. Tourism Management 28(4), 965-975.

Jalis, M. H., Zahari, M. S., Zulkifly, M. I., Othman, Z. 2009. Malaysian gastronomic tourism products: assessing the level of their acceptance among the western tourists. South Asian Journal of Tourism and Heritage 2(1), 31-4.4.

Jaume. G., Jaoqin. A. 2009. Tourist satisfaction and dissatisfaction. Annals of Tourism Research $37(1), 52-73$.

Kim, J. 2014. Antecedents of memorable tourism experiences: development of a scale to measure destination attributes associated with memorable experiences. Tourism Management $44,34-45$. 
Kim, J. H. 2017. The impact of memorable tourism experiences on loyalty behaviors: the mediating effects of destination image and satisfaction. Journal of Travel Research, 1-15.

Kim, Y. H., Kim, M., Goh, B. K. 2010. An examination of food tourist's behavior: Using the modified theory of reasoned action. Tourism Management 32(5), 1159-1165.

Kim, J. H., Ritchie, R. B. 2014. Cross-cultural validation of a memorable tourism experience scale (MTES). Journal of Travel Research 53(3), 323-335.

Kivela, J. J., Crotts, J. C. 2009. Understanding travelers' experiences of gastronomy through etymology and narration. Journal of Hospitality \& Tourism Research 33(2), 161-192.

Kotler, P. R., Bowen, J. T., Makens, J. (6th Eds.) 2014. Marketing for Hospitality and Tourism. Pearson: Essex.

Kozak, M., Rimmington, M. 20oo. Tourist satisfaction with Mallorca, Spain, as an off-season holiday destination. Journal of Travel Research 38(3), 260-269.

Loker-Murphy, L., Pearce, P. L. 1995. Young budget travelers: Backpackers in Australia. Annals of Tourism Research 22(4), 819-843.

McIntosh, A. J., Thyne, M. A. 2005. Understanding the tourist behavior using Means-End Chain Theory. Annals of Tourism Research 32(1), 259-262.

Markward, A. 2008. Backpackers: The next generation?. Retrieved from http://aut.researchgateway.ac.nz/bitstream/handle/10292/435/MarkwardA.pdf?sequence $=4$

Martin, J. C., Marrero-Rodríguez, J. R., Moreira, P., Román, C., Santana, A. 2016. How access transport mode to a World Heritage City affects visitors' experienced quality. Tourism Economics 22(2), 207-226.

Mill, R., Morrison, A. (4th Eds.) 2002. The Tourism System. Dubuque, Iowa: Kendall/Hunt Publishing.

Mohn, T. 2013, October 7. Travel boom: Young tourists spent \$217 Billion last year, more growth than any other group. Forbes. Retrieved from Forbes

Morachat, C. 2003. 'A study of destination attractiveness through tourists' perspectives'. Retrieved from http://ro.ecu.edu.au/theses/1504/

Mossberg, L. 2007. A marketing approach to the tourist experience. Scandinavian Journal of Hospitality \& Tourism 7(1), 9-74.

O’Reilly, C. C. 2006. From Drifter to Gap Year Tourist: Mainstreaming Backpacker Travel. Annals of Tourism Research 33(4), 998-1017.

Oppermann, M. 1997. First-time and Repeat visitors to New Zealand. Tourism Management 18(3), 177-181.

Page, S., Lumsdon, L. 2004. Tourism and transport: Issues and agenda for the new millennium. Elsevier Science Ltd: UK.

Paris, C. M., Teye, V. 2010. Backpacker motivations: a travel career approach. Journal of Hospitality Marketing \& Management 19(3), 244-259.

Pearce, P. L. 2005. Tourist Behavior: Themes and Conceptual Schemes (Vol. 27). Channel View Publications, UK.

Poria, Y., Biran, A., Reichel, A. 2009. Visitor's preferences for interpretation at heritage sites. Journal of Travel Research 48(1), 92-105.

Ren, L., Qiu, H., Wang, P., Lin, P. M. 2016. Exploring customer experience with budget hotels: Dimensionality and satisfaction. International Journal of Hospitality Management 52, 13-23.

Richards, G.,Wilson, J. 2004. Widening Perspectives in Backpacker Research: The Global Nomad: Backpacker Travel in Theory and Practice. Channel View Publications, Clevedon, U.K. 
Shirazi, S. M., Som, A. M. 2010. Relationship marketing and community involvement: Two significant factors for tourism strategies. Sustainable Tourism IV 139, 47.

Toxward, S. J. 1999. Backpackers' Expectations And Satisfactions A Case Study of Northland, New Zealand' Expectations And Satisfactions A Case Study Of Northland. Retrieved from https://researcharchive.lincoln.ac.nz/bitstream/handle/10182/160o/toxward_mprtm.pdf;j-

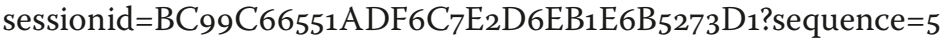

Wan, Y. K. P., Chan, S. H. J. 2013. Factors that affect the levels of tourists' satisfaction and loyalty towards food festivals: a case study of Macau. International Journal of Tourism Research 15(3), 226-240.

Weaver, D., Lawton, L. (5th Eds.) 2014. Tourism Management. Australia: Wiley \& Sons.

Wonderful Indonesia (n.d.). Accessed March 18, 2017. Available at: http://www.indonesia.travel/en.

Woo, E., Kim, H., Uysal, M. 2015. Life satisfaction and support for tourism development. Annals of Tourism Research 50, 84-97.

Yoon, Y., Uysal, M., 2005. An examination of the effects of motivation and satisfaction on destination loyalty: A structural model. Tourism Management 26(1), 45-56.

Yuksel, A. 2001. Managing customer satisfaction and retention: a case of tourist destinations, Turkey. Journal of Vacation Marketing 7(2), 153-168. 